\title{
Making the Case for Space: The Effect of Learning Spaces on Teaching and Learning
}

\author{
Terry Byers \\ Anglican Church Grammar School \& University of \\ Melbourne \\ Wesley Imms \\ Elizabeth Hartnell-Young \\ University of Melbourne
}

\begin{abstract}
An explanatory, mixed method study examined the impact of learning spaces on teachers' pedagogy, student engagement and student learning outcomes in a technology-rich school setting. Its quasi-experimental design allowed examination of differences in these variables between two settings - 'traditional' classrooms, and 'new generation learning spaces' (NGLS). Results from quantitative analyses over a one-year period indicated that particular configurations of learning spaces did have a measurable effect on how students' perceived their learning experiences and their engagement levels, with improvements often linked to NGLS. In addition, comparative analyses of experimental and control group standardised assessment data in subjects English and mathematics indicated a similar effect for the same participants. The study suggests that a single-subject, repeated measures design (SSRD) can be used to measure the outcomes effect of space on student learning outcomes. In this regard, this approach addresses a perceived lack of empirical data highlighted by recent reviews of research on this topic.
\end{abstract}

Keywords: learning environments; one-on-one technology; student learning

\section{Introduction}

The past decade has seen a resurgence in literature concerning learning environments, particularly qualitative studies or post occu- 
pancy evaluation of libraries, informal learning spaces and campus design (Painter et al., 2013). These have mostly centred on tertiary settings. From the point of view of Painter et al. (2013), a worrying characteristic of this research has been a lack of so-called 'rigorous' experimental methodologies. This, it is claimed, has been due to difficulties in randomly assigning students and staff to specific settings, and being unable to account for complex intervening variables that come to play within the educative experience. With a few notable exceptions such as Brooks $(2011,2012)$, even good quasi-experimental research is rare. The result is a paucity of systematic, empirical evidence connecting the impact of the learning space on teaching and student learning (Brooks, 2011).

Such a focus arguably results in a lack of generalizable evidence, a trend also evident in studies focusing on Secondary and Primary school settings. Here, the research has focused primarily on the designing of buildings rather than their use (Blackmore, Bateman, O'Mara, \& Loughlin, 2011). Like Painter et al. (2013), this literature review laments the seeming lack of empirical evidence concerning the impact of space on student learning. It does, however, recognise ancillary benefits from studies that are 'not fully experimental in nature' (Painter et al., 2013:7). They believe such studies contribute to the production of conceptual frameworks that can be used to structure user-centred, relationship-focused taxonomies. Such approaches contrast with previous building-focused 'post occupancy evaluation' research. This research has resulted in sound conceptual modelling of the phenomenon of space, pedagogy and technology (Brooks, 2011). A benefit of these conceptual frameworks is that they recognise that when considering a building's impact on learning, how it is inhabited is at least as important as the quality of its design (Blackmore et al., 2011).

This raises the issue of teaching practice. How teachers and students utilise space as an element of the curriculum remains an under-researched phenomenon (Chandler, 2009). It is commonly claimed that teachers' utilisation of space makes a difference to pedagogy, and must impact student learning outcome (Joint Information Systems Committee, 2006). However, it is also widely accepted that this is rarely proved - there exists a paucity of empirical evidence concerning links between learning outcomes and learning environments (Blackmore et al., 2011). Painter et al. (2013) attribute this knowledge gap to perceived deficits in available methodologies, while Blackmore et al. (2011) argue we know little about the interplay of pedagogy and space because past research has failed to focus on actual educational practices within these spaces. 
This paper addresses both these shortcomings. Firstly, it reports on a study that utilises a quasi-experimental research design to identify significant differences in student learning outcomes between two 'types' of classroom designs. Secondly, it makes use of conceptual frameworks now considered central in this discourse, to explore how learning spaces might act as a mechanism for effecting teacher pedagogical practices within a technology-enhanced environment. While small in scale, this study models an approach that owns the potential to add dramatically to current learning spaces knowledge.

\section{Context}

The study being described in this paper sought to provide evidence regarding the impact of particular qualities of the learning environment on student outcomes, student engagement, and teacher pedagogy. The site school, an independent all-boys school in Brisbane Australia, had plans to significantly overhaul its traditional classroom spaces. The school's administration required proof that their investment in the types of classroom designs being planned, and the infusion of costly technologies these designs incorporated, was warranted. While improvement in learning outcomes was not realistically anticipated during this trial, the school was interested in the potential impact of the new spaces on teachers' pedagogy and student engagement. A study was commissioned and undertaken over a full academic year. Before discussing the project, it is important to contextualise this research within the relevant conceptual frameworks that underpinned the rationale for beginning such an undertaking by the school.

\section{Built pedagogy}

One influential concept was that of 'built pedagogy'. It is based on the belief that the physical classroom space is linked to and embodies specific pedagogical practices, and shapes student learning experiences and behaviour (Thomas, 2010). Monahan (2002) develops this further with the notion of 'built pedagogy', which describes the ability of the cultural, psychological and behavioural attributes of the physical space to shape both teaching and learning. For example, from their authoritative position at the front and centre of the 'traditional' classroom, teachers are able to control and monitor students sitting in static, ordered rows (Lim, O'Halloran, \& Podlasov, 2012). This example of built pedagogy reinforces a constant pedagogical approach (Jilk, 2012), by making it natural to stand and deliver a one-way, linear flow of content transmitted through didactic pedagogy (Neill \& Etheridge, 2008). For Chandler (2009) this exemplifies the traditional view that students are passive absorbers of knowledge and information.

In many instances, digital technology as been merely superimposed 
onto traditional classroom design. This is exemplified according to Lippman (2013) by the use of singular-focal point technology, such as a data projector or interactive whiteboards, which has merely replaced the white/chalkboard. This creates a scenario in which the room layout reinforces teachers to employ teacher-centred and didatic pedagogy from the front of the room, in a similar vein to prior to integration of technology. This situation is compounded by what Lackney (2008) identifies as limited 'environmental competency', whereby teachers are not trained in how to utilise the affordance of the space with both technology and pedagogy. As a consequence, they retreat to the safety of their default practice, which in turn, from the perspective of Cleveland (2009) impedes systemic change and promotes continuation of past practices. Fisher (2010) notes that the traditional classroom design has worked against both digital technology and contemporary pedagogy due to a lack of alignment. Chandler (2009) argues that the majority of today's classrooms are designed for teachers and are predisposed to support status quo of teacher practice and the view of learning that have existed for centuries.

\section{New Generation Learning Spaces (NGLS), and 'spatial modalities'}

Another useful concept is that of 'NGLS'. There is clear consensus from the literature (Brooks, 2011, 2012; Cleveland, 2009; Fisher, 2010; Joint Information Systems Committee, 2006) that the design and attributes of the physical classroom space are very influential to both teacher practice and student learning experiences. For both Brown and Long (2006) and Fisher (2006), learning spaces need to become much more than just tight, static, hierarchical containers of learning. Instead, Oblinger (2005) puts forward the notion that their design should act as a spatial conduit, which enables the convergence of technology and contemporary pedagogy. From the perspective of Fisher (2006) and the Joint Information Systems Committee (2006), this means that these designs must embody spatial qualities that will enable both current and evolving pedagogical practices activities to be effective. This emphasis on the design, configuration and utilisation of spaces to match the specific attributes and characteristics of different pedagogical approaches, is best encapsulated by the 'learning modalities' concept developed by Fisher (2006).

The term 'New Generation Learning Spaces' (NGLS) was derived from the separate works of Radcliffe, Wilson, Powell, and Tibbetts (2008) and Jamieson (2007) that examined the merge between pedagogy, space and technology in an effort to support a shift to more student-centred and collaborative approaches to learning. For the purposes of this study an NGLS combines flexibility of furniture design 
and use (Monahan, 2002) and the integration of digital and visual technologies to create a polycentric classroom (Lippman, 2013). The 'Modalities of Learning' developed by Fisher (2006), were utilised as the principles to guide the design and attributes of the NGLS spaces, as well as the types of pedagogical activities that occurred within them. This meant that each NGLS could facilitate the three learning modes; Teacher-centred (mode 1); Student-centred (mode 2); and Informal (mode 3 ), and allow the effective transition between them within the existing structure.

\section{The study}

\section{The spaces}

The study took place within three buildings constructed between the 1940 and 1960. Each contained six classrooms classroom considered 'traditional' in layout due to chairs being set in rows, facing a teaching position at the front of the classroom. For the study, the rooms were modified to provide three spatial modalities (Fisher, 2006) within each single space. The resulting NGLS design created a complete and interactive $360^{\circ}$ learning environment through a 'polycentric layout' (Figure 1). A polycentric layout occurs when multiple teacher and student focal points are created in a space, de-emphasising what Miller-Cochran and Gierdowski (2013) refer to as the 'front' of the room. This multiple focal point layout is created using large TVs on Walls/Wheels, or TOWs (Lippman, 2013; Miller-Cochran \& Gierdowski, 2013), 'writeable walls' and multiple teacher data projector inputs. Polycentric layouts have been successfully used in North Carolina State University's StudentCentred Activities for Large Enrolment Undergraduate Program (SCALE-UP), Massachusetts Institute of Technology's Technology Enabled Active Learning (TEAL) project; and University of Minnesota's Active Learning Classrooms (ALC) project.

This focus on flexibility continued with the installation of modular and moveable furniture. Non-traditional classroom furniture such as stools, booths, ottomans and portable tables were integrated with existing desks and chairs. This was a simple and cost effective way to influence the social relationships within the space (Miller-Cochran \& Gierdowski, 2013). Based on the research of Brooks (2012), this enabled the teacher to create a range of spatial configurations, each intended to match a particular pedagogical activity. The use of soft and ergonomically designed furniture was also critical in ensuring students comfort, which for Brown and Long (2006) is one of the critical human factors in productive learning. The bright medium-cool colours on walls and throughout the furniture palette created a vibrant learning space. 


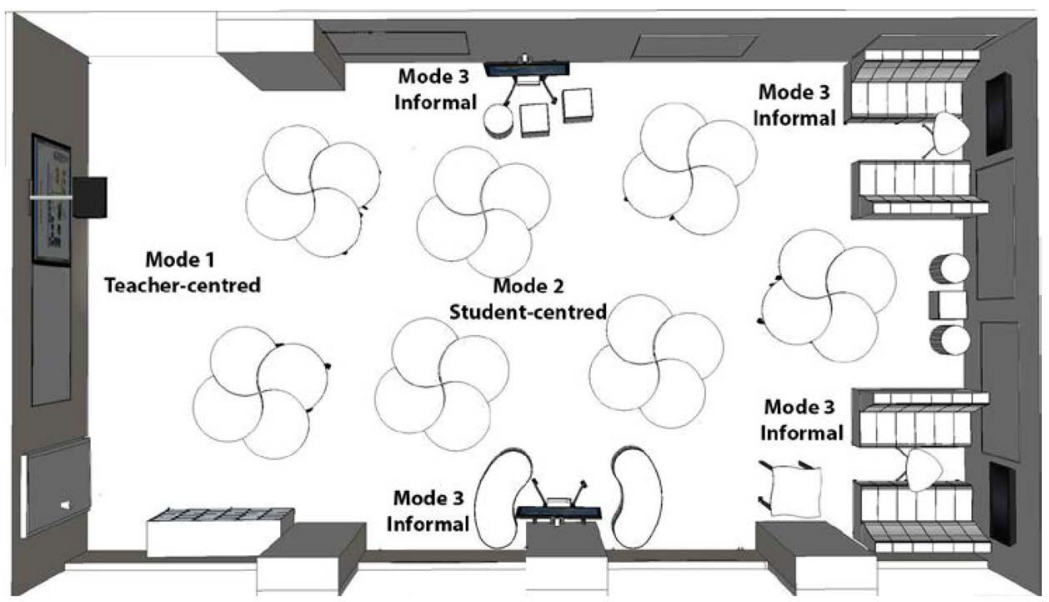

Figure 1. New generation learning space (NGLS) polycentric layout

\section{Research design}

A quasi-experimental design controlled all factors (curriculum, student ability, class construction, assessment and the teacher) except for the 'intervention'. The intervention was a retrofit of the classroom during one term break, being changed from a traditional classroom to the NGLS illustrated in Figure 1. The aim was to gather empirical evidence to evaluate the degree to which this intervention changed teacher pedagogical practices, through an explanatory mixed method. Student attitudinal data of the perceptions of their learning experiences and levels of engagement, along with learning outcomes, in the 'traditional' and NGLS classroom were quantitatively analysed to determine statistically significant differences. Insights from a follow-up teacher focus group provided a more detailed and context-specific picture that refined and explained particular statistical results and outcomes.

The research aimed to determine if changing the learning space had any effect on students' learning experiences, and their level of in-class engagement. It also sought to examine if there was any consequential impact on students' learning outcomes. These questions were addressed through an explanatory, mixed-methods research design, which systematically evaluated three research sub-questions:

1. What is the effect, if any, of NGLS on student learning experiences?

2. What is the effect, if any, of NGLS on student engagement?

3. What is the relationship, if any, of 'traditional' and NGLS, on student learning outcomes relative to their level of ability? 
A Single-subject Research Design (SSRD) addressed questions one and two. This method is common in the applied health sciences where repeated measures of a subject's activity are gathered, plotted and subjected to visual graphic analysis. The subject acts as his or her own baseline. After gathering baseline data, measures gathered during subsequent interventions can be assessed for deviations, attributable to the intervention (Bobrovitz \& Ottenbacher, 1998). With a suitable sized sample, groups can be summed and treated as one subject - as was the case in this study. SSRD suited the study's quasi-experimental approach, through each class serving as their own control and unit of analysis. A baseline/intervention (AB) design determined the effect of the intervention of the change in learning space (independent variable) on teacher pedagogy and student engagement (dependent variables). The study's sample size ( $n=164)$, high retention (96.7\%) and construct validity undertaken through Cronbachs Alpha, allowed for visual analysis of class means, with $95 \%$ confidence intervals. Visual analysis presents a succinct mechanism to identify inter- and intra-intervention trends; Bobrovitz and Ottenbacher (1998) claim it is equitable to $t$-test calculations. The application of confidence intervals as per the research of Baguley (2009), provided a superior approach to single point analysis, as it indicated the plausible range of values that the 'true' effect might take. Quantitative analysis through the calculation of effect size as suggested by Kromrey and Foster-Johnson (1996) was utilised to mitigate the 'subjective' nature of visual analysis and to prevent Type 1 errors. The work of Beeson and Robey (2006) supports the application of effect size calculations, rather than traditional inferential statistics, as they circumvent many distributional issues as the data is already auto correlated and not independent.

A repeated measures survey instrument collected student attitudinal data, using three pre- and four post-intervention collection points. The anonymous nature of the repeated measures and the maintenance of a high sample size required a mechanism to account for missing data. Any missing data was classified as Missing Completely at Random (MCAR), due to random factors such as student illness or appointments at data collection times. This was verified by Little's MCAR test and a score greater than $0.05(0.94)$. To produce a complete data set with the same Little's MCAR coefficient, the Maximum Likelihood Estimation (ML) approach was employed. This choice was justified through the work of Peugh and Enders (2004) who found that the ML approach would not artificially effect the visual analysis process, as both mean substitution and linear regression would through the truncation of variance and covariance around the mean.

To determine the effect of this intervention on student learning out- 
comes confounding variables were controlled using a range of statistical techniques. A comparison of NGLS students' pre- and post-intervention results through effect size and paired $t$-tests were calculated. The aim was to determine if the intervention had any effect on participating individuals' learning outcomes, while mitigating the variables of teacher, class composition and student ability. In addition, linear regression analysis and modelling of individual English and Mathematics academic results dependent on their corresponding standardised measure of ability was carried out. This enabled comparison of the learning outcomes of those students in the NGLS classrooms against their peers in an unchanged 'traditional' classroom, while controlling the variables of individual student cognitive ability, curriculum and assessment type and difficulty. Insights from a follow-up teacher focus group provided a more detailed and context-specific picture that explained to some degree particular statistical results and outcomes.

\section{Data Analysis}

A nine-item, five point Likert scale survey addressed research questions one and two - the effect of the learning spaces on students' learning experiences (Domain B) and students' engagement (Domain C). For the purpose of this study, 'learning experiences' related to collaborative and student-centred learning experiences facilitated by the spaces. 'Engagement' related to students' level of interest, engagement and enjoyment in each classroom space. Domain A issues in the survey were not relevant to this paper. Analysis of the summative score for each class in each of the domains, resulted in an initial Cronbach's Alpha of 0.88 (Domain B) and 0.86 (Domain C) respectively. The work of Gliem and Gliem (2003) suggests that these values indicate a very high level of internal consistency across multiple items.

\section{Results and Discussion \\ Effect of the formal learning space on student attitudinal measures}

The visual analysis of summative class means, with $95 \%$ confidence intervals, was supported by also projecting baseline data trends through the intervention phase on the graphs. Exemplars are provided in Figure 2 (below) to show 'significant' and 'non-significant' statistical differences of non-overlapping confidence intervals, using the process outlined by Horner, Swaminathan, and George (2012). Using this approach, changes in student attitudes due to the change from a traditional to NGLS classroom were proved, with clear statistical differences being found in five out of the six classes (see Table 1). In Figure 2, the unstable and positive trending baseline data set of class 7.2 and overlapping confidence interval indicates a positive but not statistically significant change in this class's attitudes to the space inter- 
vention.
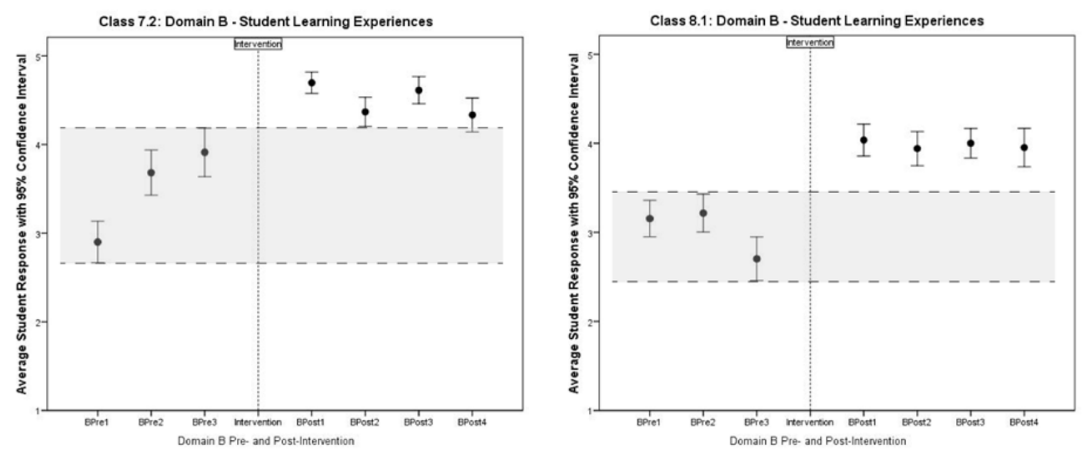

Figure 2. Visual analysis through summative means, with $95 \%$ confidence intervals, of attitudinal data in a traditional and NGLS classroom

Cohen's $d$ (mean shift), see Table 1 below, were calculated using the process outlined by Beeson and Robey (2006), to provide quantitative justification of the decisions made through visual analysis. All pre- and post-measures were utilised in the effect size calculation, to ensure a more reliable representation than a single measure. Using the thresholds suggested by Cohen (1998), the conclusions made from the visual analysis are justified through large (0.8 to 1.3$)$ to very large (greater than 1.3) effect sizes. The work of Jenson, Clark, Kircher, and Kristjansson (2007) suggests that these effect sizes equate to at least an overall improvement of 1 to 2 standard deviations from the traditional classroom class mean. Interestingly, class 7.2 achieved a slightly larger effect size in Domain B than class 8.1, even though the visual analysis process produced only a statistically significant effect in class 8.1 . This suggests that visual analysis does provide a robust means of analysis, through its ability to distinguish between results based on variation and trends throughout the baseline and intervention phases.

Table 1. Summary table of visual analysis and effect size calculations for student learning experiences and engagement

\begin{tabular}{ccccc}
\hline Class & $\begin{array}{c}\text { Student learning experiences } \\
\text { Visual analysis }\end{array}$ & $\begin{array}{c}\text { Student engagement } \\
\text { Cohen's } d \\
\text { effect size }\end{array}$ & Visual analysis & $\begin{array}{c}\text { Cohen's } d \\
\text { effect size }\end{array}$ \\
\hline 7.1 & Significant & 1.50 & Significant & 1.63 \\
7.2 & Non-significant & 1.04 & Significant & 1.38 \\
8.1 & Significant & 1.01 & Significant & 1.34 \\
8.2 & Significant & 1.31 & Significant & 1.73 \\
8.3 & Significant & 1.35 & Significant & 1.16 \\
8.4 & Significant & 2.01 & Significant & 2.48 \\
\hline
\end{tabular}


A focus group session with participating teachers was held after the quantitative analysis, in order to gain their opinion on why these results occurred. It was noteworthy that virtually all teachers involved in teaching in the NGLS attended the two-hour session, and most commented freely on their experiences. Thematic analysis of the transcripts verified that from the perspective of the participating teachers, the change in space did have a significant and positive effect on both their practice and the levels of student engagement. In many instances, teachers noted that they had made changes to their teaching practices to take advantage of the collaborative nature of the NGLS. For example, Teacher B noted that students in class 'tried to find kinds of activities that would take advantage of the resources in the room'. This notion of changed practice with changed spaced was corroborated by Teacher L, 'I really agree with Teacher B as the change forced me to reflect on my pedagogy, what I was teaching and how I was teaching ... I can't be still doing things in this room that I was doing before'. In terms of student engagement, many teachers noted a positive effect on student motivation, interest, excitement and mood in the NGLS spaces. Teacher A noted that the change to a NGLS just generated an air of excitement within the building'. Teacher $\mathrm{H}$ identified that there was 'a genuine energy and enthusiasm evident in the boys' actions in the space'. This was verified by Teacher E that 'once they started working in the new [NGLS] space, they were fully into it and there were just engrossed in the task at hand that was a significant change'.

In summary, the study found sound quantitative evidence of a positive shift in students' perceptions of their learning experiences and their levels of engagement in the NGLS, when compared to 'traditional' classrooms. This was supported to some degree by brief qualitative evidence; this latter source is to be explored further as the study progresses. Also of note is the suitability of the methodology. In a field that laments a paucity of empirical data due to difficulties in controlling myriad classroom variables (Blackmore et al., 2011; Painter et al., 2013), the SSRD proved most appropriate. The combination of visual inspection and quantitative effect size calculations of SSRD data is a suitable and robust mechanism in the determination of a statistically significant effect of an intervention. The triangulation provided through thematic analysis of the focus group, provided a reliable 'firsthand' teacher account of how the change in space somewhat forced a change away from their default practices.

\section{Effect of the learning space on student learning outcomes}

A separate analysis was conducted to address research question three, the effect of the learning spaces on students' learning outcomes. This was needed to control confounding variables - a critical component 
of any quasi-experimental design, and a reason why the complexity of the classroom has defied empirical research (Blackmore et al., 2011; Painter et al., 2013). In this study, no single approach was able to account for all variables. While the SSRD was appropriate for the questions relating to student perceptions, a stand-alone analysis of student assessment scores best suited the question regarding students' learning outcomes. In this component of the study, the variables of the teacher, student ability and class composition, were controlled through within-group effect calculations, using individual class paired $t$-tests and effect sizes. The data being utilised was school-based assessments in both English and Mathematics. The null hypothesis was that the change in the learning space from a traditional to a NGLS classroom would have no effect on student learning outcomes. A two-tailed, paired $t$-test with an alpha level of 0.05 compared participating students' assessments in these subjects taken during the time they occupied the traditional and the NGLS classrooms. The null hypothesis was rejected with nine out of the twelve results showing a statistically significant improvement in student learning outcomes (see Table 2 below). These statistically significant improvements were justified by Cohen's $d$ effect size, ranging from the upper end of the small to high effects. The 8.1 and 8.3 mathematics classes composed of high-ability students had non-significant improvements and negligible effect sizes. From the focus group, the teacher of both classes indicated that due to high preintervention learning outcomes, there is less room for improvement through the subsequent effect of the intervention, compared to the other classes with a wider range of student abilities.

Table 2. Summary table of paired t-test and effect size calculations comparing pre- and post-NGLS intervention English and mathematics results

\begin{tabular}{ccclc}
\hline Class & Subject & Sig. (2-tailed) & $d$ & Decision \\
\hline 7.1 & English & .030 & .47 & Reject \\
& Mathematics & .001 & .68 & Reject \\
7.2 & English & .007 & .55 & Reject \\
& Mathematics & .001 & .63 & Reject \\
8.1 & English & .046 & .32 & Reject \\
& Mathematics & .307 & .21 & Accept \\
8.2 & English & .506 & .12 & Accept \\
& Mathematics & .026 & .46 & Reject \\
8.3 & English & .001 & .51 & Reject \\
& Mathematics & .780 & .16 & Accept \\
8.4 & English & .001 & .40 & Reject \\
& Mathematics & .003 & .32 & Reject \\
\hline
\end{tabular}


The variables of the curriculum, student ability and the assessment mechanism assessment type and difficulty were controlled by comparing all Year 7 and 8 English and mathematics learning outcomes against their standardised academic ability. The Academic Assessment Services Placement/Entrance exam was utilised to determine individual students Verbal (English) and Non-Verbal (Mathematics) Reasoning scaled scores. These scaled scores, which are normed to the population, represented a valid and reliable measure of individual student ability. A linear regression compared the NGLS students to their peers in an unaltered traditional classroom (see Table 3 below). In each of the linear regressions, the students in the NGLS cohorts outperformed their 'like-ability peers' in both English and Mathematics.

Table 3. A comparison of Linear Regression of English and Mathematics Learning Outcomes dependent on Cognitive Ability of the Traditional and NGLS classes

\begin{tabular}{|c|c|c|c|c|c|}
\hline Year & Subject & Classroom & Composite score & Constant & $\mathrm{R} 2$ \\
\hline \multirow[t]{2}{*}{7} & English & NGLS & $.54^{*}$ & $7.80 *$ & .19 \\
\hline & & Traditional & $.51^{*}$ & $7.83^{*}$ & .20 \\
\hline \multirow[t]{2}{*}{7} & Mathematics & NGLS & $.62^{*}$ & $8.13^{*}$ & .32 \\
\hline & & Traditional & $.85^{*}$ & $5.86^{*}$ & .46 \\
\hline \multirow[t]{2}{*}{8} & English & NGLS & $.34^{*}$ & $9.43^{*}$ & .12 \\
\hline & & Traditional & $.33^{*}$ & $7.70^{*}$ & .10 \\
\hline \multirow[t]{2}{*}{8} & Mathematics & NGLS & $.91^{*}$ & $5.57^{*}$ & .45 \\
\hline & & Traditional & $.77^{*}$ & $4.18^{*}$ & .17 \\
\hline
\end{tabular}

The closest linear model occurred in Year 7 English, with only a small (+0.03) improvement in composite score and a similar adjusted $\mathrm{R}^{2}$ value. In Year 7 Mathematics, the NGLS classes clearly outperformed their like-ability peers in the unaltered classroom, with a constant that was +2.27 points higher and equated to approximately two-thirds of a grade. The composite score of the traditional classroom results, was inflated by the instance of two 'high-ability' mathematics classes within the traditional data set that negatively skewed this result. For Year 8 English, both the constant $(+1.73)$ and composite $(+.01)$ were higher and translated to a stable improvement between one- to two-thirds of a 15-point scale grade. Finally, in Year 8 Mathematics both the constant $(+1.39)$ and composite $(+0.14)$ were higher and translated to a stable difference between one- to two-thirds of a grade.

In summary, the quasi-experimental design and the confounding variables control mechanisms, through which these results were obtained, produced a robust set of results similar to that reported by Brooks $(2011,2012)$. It is clear from the empirical evidence obtained 
in this study that there is a positive link between the types of learning spaces and student learning outcomes in a school environment. However, this initial evidence requires validation through additional studies and in different contexts, to ensure generalizability.

\section{Conclusion}

The topic of learning spaces has received significant attention in the school sector, with many schools investing in significant capital works. However, what has been lacking is empirical study of the effect of these spaces on the learning experiences and engagement of school-age students. In particular, studies are required that directly evaluate student learning outcomes within a technology-enabled setting. The aim of this study was to provide initial empirical evidence to assess the impact of NGLS on teaching and learning over the period of a year. The findings presented here point to a positive and significant effect of the NGLS, regarding both how students view their learning experiences, and perceive their level of engagement. The quasi-experimental design with resulting control of confounding variables isolated the link between the learning space and student learning outcomes. Therefore, the improved student academic performance and their outperformance of like-ability peers do point to a link between NGLS and improved learning outcomes. These findings advance our knowledge of learning spaces in a school setting, both in terms of proving in one setting that space does matter, and in validating a robust method for exploring this topic. However, the central questions in this research remain to be generalised across a wider population: What effect does technology play in NGLSs and how does it affect student learning experience and engagement? What is the influence of the teacher in a NGLS and how does it affect their pedagogical practice? Is there a link between improved teacher environmental competency, and student engagement and learning outcomes? With the longitudinal nature of this study, these questions will be addressed in subsequent papers.

\section{Acknowledgements}

The authors would like to acknowledge the support of the Anglican Church Grammar School, and the Learning Environments Applied Research Network (LEaRN) in the preparation of this article.

\section{References}

Baguley, T. (2009). Standardized or simple effect size: What should be reported? The British Journal of Psychology. 100(3), 603-617. http://dx.doi.org/10.1348/000712608X377117

Beeson, P. M. \& Robey, R. R. (2006). Evaluating single-subject treatment research: Lessons learned from the aphasia literature. Neuropsychology Review. 16(4), 161-169. http://dx.doi.org/10.1007/s11065-006-9013-7

Blackmore, J., Bateman, D., O’Mara, J. \& Loughlin, J. (2011). Research into the 
connection between built learning spaces and student outcomes: Literature review. Melbourne: Victorian Department of Education and Early Childhood Development Retrieved from http://www.eduweb.vic.gov.au/edulibrary/ public/publ/research/publ/blackmore_learning_spaces.pdf.

Bobrovitz, C. D. \& Ottenbacher, K. J. (1998). Comparison of visual inspection and statistical analysis of single-subject data in rehabilitation research. American Journal of Physical Medicine \& Rehabilitation. 77(2), 94-102. http://dx.doi.org/10.1097/00002060-199803000-00002

Brooks, D. C. (2011). Space matters: The impact of formal learning environments on student learning. British Journal of Educational Technology. 42(5), 719-726.

http://dx.doi.org/10.1111/j.1467-8535.2010.01098.x

Brooks, D. C. (2012). Space and consequences: The impact of different formal learning spaces on instructor and student behavior. Journal of Learning Spaces. 1(2), 1-10.

Brown, M. \& Long, P. (2006). Trends in learning space design. In D. G. Oblinger (Ed.), Learning Spaces (pp. 9.1 - 9.11). Washington D.C: EDUCAUSE. Retrieved from http://net.educause.edu/ir/library/pdf/PUB7102.pdf.

Chandler, W. L. (2009). A" teacher space or a learner place?: Reconsidering the classroom environment. International Journal of Learning. 16(9), 261-267.

Cleveland, B. W. (2009). Engaging Spaces: An investigation into middle school educational opportunities provided by innovative built environments. A new approach to understanding the relationship between learning and space. International Journal of Learning. 16(5), 385-397.

Cohen, J. (1998). Statistical power analysis for the behavioral sciences (2nd ed.). Erlbaum: New Jersey.

Fisher, K. D. (2006). The new learning environment: Hybrid designs for hybrid learning. Retrieved from http:/www.woodsbagot.com/en/Documents/ Public_Research/PUBLIC2\%20The\%20New\%20Learning\%20Environment.pdf

Fisher, K. D. (2010). Technology-enabled active learning environments: An appraisal. CELE Exchange. Centre for Effective Learning Environments, 2010(6-10), 1-8.

Gliem, J. A. \& Gliem, R. R. (2003). Calculating, interpreting, and reporting cronbach's alpha reliability coefficient for likert-type scales. Paper presented at the Midwest Research-to-Practice Conference in Adult, Continuing, and Community Education, The Ohio State University, Columbus.

Horner, R. H., Swaminathan, H. S. \& George, S. K. (2012). Considerations for the systematic analysis and use of single-case Research. Education \& Treatment of Children. 35(2), 269. http://dx.doi.org/10.1353/etc.2012.0011

Jamieson, P. (2007). Creating new generation learning environments on the university campus. Retrieved from http://www.woodsbagot.com/en/ Documents/Public_Research/WB5307_U21_FA-7_final.pdf

Jenson, W. R., Clark, E., Kircher, J. C. \& Kristjansson, S. D. (2007). Statistical reform: Evidence-based practice, meta-analyses, and single subject designs. Psychology in the Schools. 44(5), 483-493. http://dx.doi.org/10.1002/pits.20240

Jilk, B. A. (2012). Place making and change in learning environments. In M. Dudek (Ed.), Children's Spaces (pp. 14). Hoboken: Taylor \& Francis.

Joint Information Systems Committee. (2006). Designing spaces for effective learning: A guide to 21st century learning space design. Higher Education 
Funding Council for England (HEFCE) on behalf of JISC.

Kromrey, J. D. \& Foster-Johnson, L. (1996). Determining the efficacy of intervention: The use of effect sizes for data analysis in single-subject research. Journal of Experimental Education. (1), 73-93.

http://dx.doi.org/10.1080/00220973.1996.9943464

Lackney, J. A. (2008). Teacher environmental competence in elementary school environments. Children, Youth and Environments. 18(2), 133-159.

Lim, F. V., O’Halloran, K. L. \& Podlasov, A. (2012). Spatial pedagogy: Mapping meanings in the use of classroom space. Cambridge Journal of Education. 42(2), 235-251. http://dx.doi.org/10.1080/0305764X.2012.676629

Lippman, P. C. (2013). Designing collaborative spaces for schools: Part 1. The Journal, January. Retrieved from http://thejournal.com/articles/2013/02/13/ designing-collaborative-spaces-for-schools.aspx

Miller-Cochran, S. \& Gierdowski, D. (2013). Making peace with the rising costs of writing technologies: Flexible classroom design as a sustainable solution. Computers and Composition. 30(1), 50-60.

http://dx.doi.org/10.1016/j.compcom.2012.12.002

Monahan, T. (2002). Flexible space \& built pedagogy: Emerging IT embodiments. Inventio. 4(1), 1-19.

Neill, S. \& Etheridge, R. (2008). Flexible learning spaces: The Integration of pedagogy, physical design, and instructional technology. Marketing Education Review. 18(1), 47-54.

Oblinger, D. G. (2005). Leading the transition from classrooms to learning spaces. EDUCAUSE Quarterly. 1(7-12).

Painter, S. et al. (2013). Research on learning space design: Present state, future directions The Perry Chapman Prize: Society for College and University Planning.

Peugh, J. L. \& Enders, C. K. (2004). Missing data in educational research: A review of reporting practices and suggestions for improvement. Review of Educational Research. 74(4), 525-556.

http://dx.doi.org/10.3102/00346543074004525

Radcliffe, D., Wilson, H., Powell, D. \& Tibbetts, B. (2008). Designing next generation places of learning: collaboration at the pedagogy-space-technology nexus The University of Queensland. Brisbane.

Thomas, H. (2010). Learning spaces, learning environments and the dis'placement' of learning. British Journal of Educational Technology. 41(3), 502-511 [Article]. http://dx.doi.org/10.1111/j.1467-8535.2009.00974.x 